\title{
THE ALVEOLAR-ARTERIAL OXYGEN PRESSURE GRADIENT IN MITRAL STENOSIS ${ }^{\text {? }}$
}

\author{
By S. GILBERT BLOUNT, JR., MALCOLM C. MCCORD,2 AND \\ LEIGHTON L. ANDERSON \\ (From the Cardiovascular Pulmonary Laboratory, Department of Medicine, University of \\ Colorado School of Medicine, Denver, Colo.)
}

(Submitted for publication April 28, 1952; accepted July 7, 1952)

In $1931 \mathrm{zu}$ Jeddeloh (1) reported his observations on the alterations in the alveolar walls in chronic passive congestion. Parker and Weiss (2) in 1936 sharply focused attention upon these changes, particularly in patients with "tight" mitral stenosis. These authors demonstrated the dilatation of the capillaries and the thickening of the alveolar walls that occurred secondary to chronic engorgement of the pulmonary capillary bed. Larrabee, Parker, and Edwards (3) confirmed these findings in recent studies.

These structural changes at the level of the alveolar-capillary membrane might be expected to interfere with the diffusion of oxygen across this membrane. Decreased oxygen saturation of the peripheral arterial blood has been frequently observed in patients with mitral stenosis. This fact would suggest the possibility that the blood leaving a significant fraction of the pulmonary capillaries had not been fully oxygenated. Thus, it was suggested that a physiologic counterpart to the known pathologic changes might be present and effect a change in the normal alveolar-capillary oxygen tension gradient.

The present report deals with the determination of this gradient in patients with "tight" mitral stenosis.

\section{MATERIAL AND METHODS}

The normal values were determined from studies of 20 medical students in good health. There were three females and 17 males with an average age of 26.1 years. Observations were made on 18 patients with rheumatic heart disease and mitral stenosis. The average age of these patients was 31.7 years, with the sexes equally divided. In two patients organic tricuspid regurgitation was also present, and, in a third, aortic stenosis was present. The degree of their incapacitation was only mild to

1 This study was supported by a grant (H-241) from the United States Public Health Service.

2 Public Health Service Postdoctorate Research Fellow of the National Heart Institute. moderate. Nine of the patients were classified in group II, and nine in group III by the criteria of the New York Heart Association (4).

Arterial blood was obtained through an indwelling needle in the brachial artery with the patient supine. At least five minutes were allowed after placement of the needle before withdrawing blood. Oxygen content and capacity and carbon dioxide content were determined in duplicate using the Van Slyke-Neill (5) manometric method. The arterial blood for oxygen tension determination was withdrawn simultaneously with the collection of the expired air for a one and one-half minute period. The partial pressures of oxygen and carbon dioxide in the arterial blood were determined by the direct technique of Riley, Proemmel, and Franke (6). The alveolar partial pressure of oxygen was calculated using the alveolar equation in the form presented by Pappenheimer and his associates (7), substituting arterial $\mathrm{PCO}_{2}$ for alveolar $\mathrm{PCO}_{2}$. The alveolar-arterial oxygen pressure gradient was then calculated. Venous cardiac catheterization was performed in all patients in the mitral group. Procedures were carried out at average ambient temperature of $23.5^{\circ}$ C. and a barometric pressure of $623 \mathrm{~mm}$. $\mathrm{Hg}$. These determinations were then repeated with exercise, using a bicycle arrangement with the patient in a supine position. The amount of exercise was that sufficient to produce subjective fatigue.

\section{RESULTS}

The pertinent data from the normal subjects are shown in Table I and from the patients with mitral stenosis in Table II. A significant difference existed between the mean values for resting arterial oxygen in the tension in the two groups. The mean value for the normal subjects was $74.8 \mathrm{~mm}$. $\mathrm{Hg}$ and for the patients with mitral stenosis 66.3 $\mathrm{mm}$. Hg. No significant difference existed between the mean values of alveolar oxygen tension in the two groups at rest. The resting alveolararterial oxygen tension gradient was significantly higher in the mitral stenosis group than in the normal group; the levels being $11.6 \mathrm{~mm}$. $\mathrm{Hg}$ and $4.8 \mathrm{~mm} . \mathrm{Hg}$, respectively.

The arterial oxygen tension during exercise was not significantly altered from the resting val- 
TABLE I

The oxygen tension values in the normal subjects

\begin{tabular}{|c|c|c|c|c|c|c|}
\hline \multirow[t]{2}{*}{ Subject } & \multicolumn{2}{|c|}{$\begin{array}{c}\text { Arterial oxygen } \\
\text { tension } \\
(\mathrm{mm} . \mathrm{Hg})\end{array}$} & \multicolumn{2}{|c|}{$\begin{array}{c}\text { Alveolar oxygen } \\
\text { tension } \\
(m m . H g)\end{array}$} & \multicolumn{2}{|c|}{$\begin{array}{c}\text { Alveolar-arterial } \\
\text { oxygen tension } \\
\text { gradient } \\
(\mathbf{m m} \cdot \mathbf{H g})\end{array}$} \\
\hline & Rest & Exercise & Rest & Exercise & Rest & Exercise \\
\hline 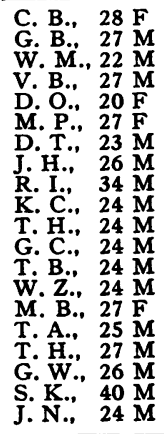 & $\begin{array}{l}76.4 \\
69.8 \\
79.3 \\
84.1 \\
74.9 \\
75.4 \\
72.2 \\
75.1 \\
74.1 \\
68.7 \\
71.3 \\
70.2 \\
71.8 \\
71.2 \\
69.4 \\
70.0 \\
85.7\end{array}$ & $\begin{array}{l}87.4 \\
83.2 \\
81.5 \\
71.4 \\
73.8 \\
77.4 \\
72.7 \\
77.4 \\
76.0 \\
72.8 \\
68.7 \\
75.9 \\
71.6 \\
72.5 \\
67.8 \\
71.8 \\
80.2 \\
80.8 \\
67.2 \\
75.4\end{array}$ & $\begin{array}{l}74.0 \\
70.9 \\
78.0 \\
91.9 \\
83.5 \\
83.8 \\
73.7 \\
82.5 \\
79.9 \\
74.9 \\
77.8 \\
68.7 \\
67.9 \\
73.6 \\
77.2 \\
72.7 \\
95.3 \\
94.2 \\
77.0 \\
94.5\end{array}$ & $\begin{array}{l}95.5 \\
88.3 \\
86.1 \\
82.6 \\
87.3 \\
86.1 \\
83.4 \\
85.7 \\
87.1 \\
83.7 \\
77.5 \\
82.9 \\
86.3 \\
78.7 \\
89.3 \\
83.4 \\
85.6 \\
98.8\end{array}$ & $\begin{array}{r}-2.4 \\
1.1 \\
-1.3 \\
7.8 \\
8.6 \\
8.4 \\
1.5 \\
7.4 \\
5.8 \\
6.2 \\
6.5 \\
-1.5 \\
-3.9 \\
2.4 \\
7.8 \\
2.7 \\
9.6 \\
9.1 \\
7.0 \\
12.7\end{array}$ & $\begin{aligned} 8.1 \\
5.1 \\
4.6 \\
11.2 \\
13.5 \\
8.7 \\
10.7 \\
8.3 \\
11.1 \\
10.9 \\
8.8 \\
7.0 \\
14.7 \\
6.2 \\
21.5 \\
11.6 \\
5.4 \\
18.0 \\
21.4 \\
6.9\end{aligned}$ \\
\hline $\begin{array}{l}\text { Mean } \\
\text { Standard } \\
\text { error of } \\
\text { the mean }\end{array}$ & $\begin{array}{c}74.8 \\
\pm 1.27\end{array}$ & $\begin{array}{r}75.3 \\
\pm 1.23\end{array}$ & $\begin{array}{r}79.6 \\
\pm 1.97\end{array}$ & $\begin{array}{r}86.0 \\
\pm 1.13\end{array}$ & $\begin{array}{r}4.8 \\
\pm 1.06\end{array}$ & $\begin{array}{c}10.7 \\
\pm 1.15\end{array}$ \\
\hline
\end{tabular}

ues in either group. The alveolar oxygen tension level, however, rose to $86.0 \mathrm{~mm} . \mathrm{Hg}$ in the normal group and to $83.9 \mathrm{~mm}$. $\mathrm{Hg}$ in the group with mitral stenosis. The alveolar-arterial oxygen tension gradient on exercise was thereby increased to $10.7 \mathrm{~mm}$. $\mathrm{Hg}$ for the normal subjects and to $15.5 \mathrm{~mm} . \mathrm{Hg}$ in the group with mitral stenosis.

The mean arterial oxygen saturation at rest

TABLE II

The oxygen tension values in the patients with mitral stenosis

\begin{tabular}{|c|c|c|c|c|c|c|}
\hline \multirow[t]{2}{*}{ Subject } & \multicolumn{2}{|c|}{$\begin{array}{c}\text { Arterial oxygen } \\
\text { tension } \\
(\mathrm{mm} . \mathrm{Hg})\end{array}$} & \multicolumn{2}{|c|}{$\begin{array}{c}\text { Alveolar-oxygen } \\
\text { tension } \\
(\mathrm{mm} . \mathrm{Hg})\end{array}$} & \multicolumn{2}{|c|}{$\begin{array}{c}\text { Alveolar-arterial } \\
\text { oxygen tension } \\
\text { gradient } \\
(\boldsymbol{m} m . \mathbf{H g})\end{array}$} \\
\hline & Rest & Exercise & Rest & Exercise & Rest & Exercise \\
\hline 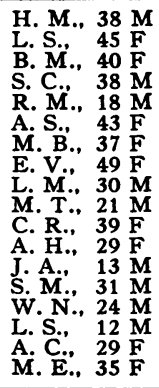 & $\begin{array}{l}65.6 \\
52.3 \\
70.0 \\
62.0 \\
74.5 \\
559.1 \\
70.3 \\
75.2 \\
71.4 \\
63.0 \\
72.2 \\
57.5 \\
60.5 \\
60.8 \\
67.0 \\
75.3 \\
73.5 \\
63.0\end{array}$ & $\begin{array}{l}74.2 \\
67.3 \\
71.5 \\
68.2 \\
75.9 \\
69.1 \\
55.3 \\
77.1 \\
58.5 \\
71.0 \\
60.1 \\
56.7 \\
64.9 \\
75.9 \\
70.9 \\
79.7 \\
66.7\end{array}$ & $\begin{array}{l}84.3 \\
61.9 \\
84.0 \\
71.9 \\
85.5 \\
73.0 \\
84.8 \\
76.3 \\
82.3 \\
79.4 \\
77.3 \\
80.8 \\
61.0 \\
73.2 \\
68.8 \\
95.5 \\
83.9 \\
78.3\end{array}$ & \begin{tabular}{|r|}
86.4 \\
76.7 \\
78.7 \\
89.5 \\
95.5 \\
83.3 \\
77.2 \\
88.6 \\
75.1 \\
83.0 \\
79.8 \\
60.8 \\
78.0 \\
95.9 \\
88.0 \\
100.0 \\
89.9
\end{tabular} & $\begin{aligned} 18.7 \\
9.6 \\
14.0 \\
9.9 \\
11.0 \\
13.9 \\
14.5 \\
1.1 \\
10.9 \\
16.4 \\
5.1 \\
23.3 \\
0.5 \\
12.4 \\
1.8 \\
20.2 \\
10.4 \\
15.3\end{aligned}$ & $\begin{array}{rl}12.2 & 9.4 \\
7.2 \\
21.3 \\
19.8 \\
14.2 \\
21.9 \\
11.5 \\
16.6 \\
12.0 \\
19.7 \\
4.1 \\
13.1 \\
20.0 \\
17.1 \\
20.3 \\
23.2\end{array}$ \\
\hline $\begin{array}{l}\text { Mean } \\
\text { Standard } \\
\text { error of } \\
\text { the mean }\end{array}$ & $\begin{array}{r}66.3 \\
\pm 1.67\end{array}$ & $\begin{array}{r}68.4 \\
\pm 1.84\end{array}$ & $\begin{array}{r}77.9 \\
\pm 2.10\end{array}$ & \pm 2.38 & $\begin{array}{l}11.6 \\
\pm 1.56\end{array}$ & $\begin{array}{r}15.5 \\
\pm 1.40\end{array}$ \\
\hline
\end{tabular}

was 92.1 per cent in the patients with mitral stenosis and 94.1 per cent in the normal subjects.

The resting minute ventilation per square meter of body surface was 3.31 liters in the normal group and 4.12 liters in the mitral stenosis group. The mean arterio-venous oxygen difference in the mitral stenosis group was 5.69 volumes per cent at rest and 9.30 volumes per cent on exercise. The mean cardiac index in the patients with mitral stenosis was 2.74 liters at rest and 3.53 liters on exercise.

\section{DISCUSSION}

There was a significant reduction in the arterial blood oxygen tension in the group with mitral stenosis as compared to the normal group, while the alveolar oxygen tension revealed no significant difference between the two groups. The resulting alveolar-arterial oxygen pressure gradient was thus significantly greater in the mitral group due to the lower arterial blood oxygen tension in this group.

Since on the average the alveolar oxygen tensions were very nearly the same in the normal subjects and in the patients with mitral stenosis, there are two main factors to be considered in an evaluation of the lowered arterial oxygen tension in the patients with mitral stenosis. These are venous admixture, in the expanded sense defined by Riley and Cournand (8), and alveolar-capillary oxygen diffusion. There is some admixture of poorly oxygenated blood to the well oxygenated blood leaving the alveolar capillaries even in normal persons. The principal channels through which this takes place are the bronchial radicles draining into the pulmonary veins, the myocardial venous channels draining into the left heart, and the pulmonary capillaries that are perfusing imperfectly aerated alveoli. The oxygen content of the mixed venous blood was lower in the patients with mitral stenosis than in normal subjects and on exercise there was a considerable further decrease in the oxygen content of the mixed venous blood. This would tend to accentuate the normal effect of the admixture of venous blood upon lowering the arterial oxygen tension. This mechanism has been proposed by Ryan and Hickam (9) as an explanation of the lowered arterial oxygen tension and increased alveolar-arterial oxygen pressure gradient in patients with anemia. 
Sample calculations using charts prepared by Riley, Cournand, and Donald (10) would indicate that marked impairment of diffusion beyond the realm of probability would have to be present in order to influence significantly the alveolar-capillary difference. The level of alveolar oxygen tension was so high in these patients that abnormalities of diffusion, if present, were not manifested by appreciable contributions to the alveolar-arterial oxygen pressure gradient. This does not necessarily indicate that there is no impairment of diffusion in patients with mitral stenosis as the circumstances under which this study was performed were not such as to determine this factor.

To determine diffusion impairment at the alveolar-capillary membrane level studies as presented in this report must be performed at two levels of oxygenation as described by Riley, Cournand, and Donald (10). The two levels of oxygenation are designed to effect a definite and significant change in the relative magnitude of the two components of the alveolar-arterial oxygen pressure gradient; namely, diffusion and venous admixture. Such studies are now in progress in this laboratory.

\section{SUMMARY AND CONCLUSIONS}

1. The arterial oxygen tension, alveolar oxygen tension and the resulting alveolar-arterial oxygen pressure gradient have been determined in 20 normal subjects and in 18 patients with mitral stenosis at rest and with exercise.

2. At rest the mitral group had a normal alveolar oxygen tension, a significantly decreased arterial oxygen tension, and a resulting increased alveolararterial oxygen pressure gradient as compared with the normal control group.

3. On exercise the alveolar oxygen tension rose in both groups and the arterial oxygen tension remained essentially unchanged in both groups.

4. The increased alveolar-arterial oxygen pressure gradient in patients with mitral stenosis, as determined under the conditions of the present study, may be explained on the basis of increased venous admixture.

\section{REFERENCES}

1. zu Jeddeloh, B., Untersuchungen zur Histologie chronischer Stauungslungen. Gleichzeitig ein Beitrag zur normalen Histologie der Lunge. Beitr. path. Anat., 1931, 86, 387.

2. Parker, F. Jr., and Weiss, S., The nature and significance of the structural changes in the lungs in mitral stenosis. Am. J. Path., 1936, 12, 573.

3. Larrabee, W. F., Parker, R. L., and Edwards, J. E., Pathology of intrapulmonary arteries and arterioles in mitral stenosis. Proc. Staff Meet., Mayo Clin., 1949, 24, 316.

4. The Criteria Committee of the New York Heart Association, Nomenclature and Criteria for Diagnosis of Diseases of the Heart. New York Heart Association, 1939, 4th ed.

5. Van Slyke, D. D., and Neill, J. M., The determination of gases in blood and other solutions by vacuum extraction and manometric measurement. I. J. Biol. Chem., 1924, 61, 523.

6. Riley, R. L., Proemmel, D. D., and Franke, R. E., A direct method for determination of oxygen and carbon dioxide tensions in blood. J. Biol. Chem., 1945, 161, 621.

7. Standardization of definitions and symbols in respiratory physiology. Federation Proc., 1950, 9, 602.

8. Riley, R. L., and Cournand, A., "Ideal" alveolar air and the analysis of ventilation-perfusion relationships in the lungs. J. Appl. Physiol., 1949, 1, 825.

9. Ryan, J. M., and Hickam, J. B., The alveolar-arterial oxygen pressure gradient in anemia. J. Clin. Invest., 1952, 31, 188.

10. Riley, R. L., Cournand, A., and Donald, K. W., Analysis of factors affecting partial pressures of oxygen and carbon dioxide in gas and blood of lungs : methods. J. Appl. Physiol., 1951, 4, 102. 